\title{
The effect of some disiloxane chain extenders on the thermal and mechanical properties of cross-linked poly(siloxane-urethane)s
}

\author{
E. Pusztai ${ }^{1 *}$, Cs. Kenyó ${ }^{2}, J$. Nagy $^{1}, \ddot{O}$. Wagner $^{1}$ \\ ${ }^{1}$ Budapest University of Technology and Economics, Department of Inorganic and Analytical Chemistry, H-1111 \\ Budapest, Szent Gellért tér 4., Hungary \\ ${ }^{2}$ Budapest University of Technology and Economics, Department of Physical Chemistry and Materials Science, H-1111 \\ Budapest, Müegyetem rkp. 3., Hungary
}

Received 11 December 2012; accepted in revised form 2 February 2013

\begin{abstract}
Poly(siloxane-urethane) (PSiU) networks based on a bis(hydroxyorgano) disiloxane chain extender, a trifunctional polyether polyol as a cross-linker, methylene-diphenyl diisocyanate and $\alpha, \omega$-hydroxyethoxyethyl polydimethylsiloxane were synthesized in butyl acetate solution. The effect of the chain extenders and the cross-link density was investigated by using thermogravimetric analysis (TGA), dynamic mechanical thermal analysis (DMTA), swelling, hardness and tensile strength measurements. Isotherm thermogravimetric analyses were carried out for selected polymer compositions at 120 and $170^{\circ} \mathrm{C}$ and also the changes in tensile strength were followed. The different chain extenders have a strong effect on the hard segment structure, thus on the thermal and mechanical behaviour. The phase separation of the soft and hard segments was indicated by the two or three well distinguished tan $\delta$ peaks, the maxima of which range within wide intervals depending on the polymer composition. The polymers of high cross-link density showed a very good thermal stability, high tensile strength (up to 68.7 MPa) and hardness (80-95 Shore A) even of high 13-36\% dimethyl siloxane content. Changing the siloxane soft segment ratio and the cross-link density the physical properties can be adjusted.
\end{abstract}

Keywords: biocompatible polymers, poly(siloxane urethane) networks, thermal properties, mechanical properties, coatings

\section{Introduction}

Poly(siloxane-urethane) (PSiU) copolymers and networks have attracted a lot of researchers' attention for decades owing to the potential of blending the unique properties of polysiloxanes (PSi) and polyurethanes (PU). Combining the weather resistance, the biocompatibility (or hemocompatibility) and the thermal stability of PSis and the excellent mechanical properties of PUs makes PSiUs applicable as coating [1, 2], medical [3] or flame retardant [4] materials. PSiUs, first of all their mechanical properties, still have challenges for researchers.
PSiU and silicone-urea segmented copolymers were investigated by numerous research groups to understand the relationship between their structure and thermal or mechanical behaviour [5-10]. It was found that the polysiloxane chains are phase separated from the hard segments (HS), consisting of mostly 4,4'-methylene diphenylene diisocyanate (MDI) and 1,4-butanediol (BDO), and also from the polyether soft segments (SS). The two-phase structure was observable also by polarized light microscopy; and on transmission electron microscopy (TEM) images the phase-separated morphology did not seem to be dependent on the urethane structure

\footnotetext{
*Corresponding author, e-mail: pusztaierika@hotmail.com (C) BME-PT
} 
but on the used solvent [5]. Silicon based polyurethanes reflected the immiscibility of the inorganic/ organic building blocks. There were several attempts to moderate the phase separation. With the optimal ratio of PSi [6] by using a comacrodiol [11] or different chain extenders $[12,13]$, the segment compatibility and in this way the mechanical and thermal properties could be improved. The cross-linked PSiUs also showed improved physical characteristics $[2,14,15]$.

The thermal degradation of PSiU copolymers and networks was investigated in details in several papers $[13,16,17]$. The isothermal thermogravimetry is one of the best methods to investigate thermal stability [18]. The thermal degradation of PSiUs was studied by using thermogravimetric analysis (TGA) $[2,13$, 14] sometimes coupled with a Fourier transform infrared spectroscopy (TG-FTIR) [16, 17], but the isothermal thermogravimetric analysis was usually not favoured [19]. In an earlier work thermal degradation of segmented PSiUs were observed to occur in two steps [13], later in the case of PSiU copolymers two basic steps and further sub-steps were revealed [17]; in some recent papers four steps were distinguished at various PSiU copolymers and networks $[14,16]$. An improved thermal stability was obtained with poly(siloxane-urethane-imide) copolymers $[16,19]$.

The relationship between the structure and the mechanical properties of PSiUs was investigated extensively by using the dynamic mechanical thermal analysis (DMTA) [11, 12, 14, 15]. Depending on the composition of the polymers two or three glass transition temperatures $\left(T_{\mathrm{g}}\right)$ were observed according to $\tan \delta$, which indicates the phase separation. One $T_{\mathrm{g}}$ was observed from -128 to $-90^{\circ} \mathrm{C}$, which belongs to the glass transition of the siloxane soft segments, and $T_{\mathrm{g}}$ of the hard segments ranges between -15 and $+85^{\circ} \mathrm{C}$ strongly depending on the structure of the HS. The cross-linked PSiUs showed definitely higher $T_{\mathrm{g}}$-s, and different chain extenders had also very strong effect on the $T_{\mathrm{g}}$ of the HS [11, $12,15]$.

The aim of our work was to synthesize new, crosslinked PSiUs by applying different bis(hydroxyalkyl) functional disiloxanes such as 1,3-bis(6hydroxyhexanoylmethyl)-1,1,3,3-tetramethyl disiloxane (SIKOL, $M_{\mathrm{w}}=422 \mathrm{~g} / \mathrm{mol}$ ), 1,3-bis(hydroxyethoxypropyl)-1,1,3,3-tetramethyl disiloxane (SIPA, $\left.M_{\mathrm{w}}=338 \mathrm{~g} / \mathrm{mol}\right)$, 1,3-bis(2-hydroxypropanoyl-

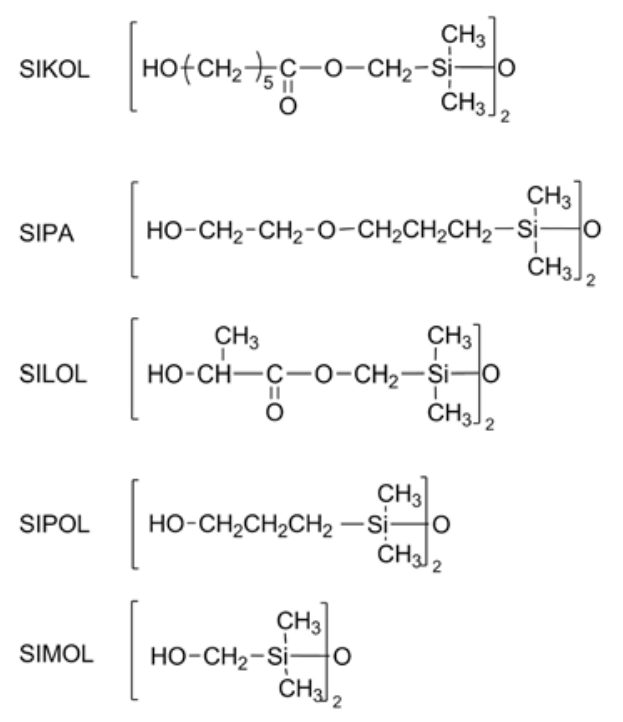

Figure 1. Molecular formula of the applied disiloxane chain extenders

methyl) tetramethyl disiloxane (SILOL, $M_{\mathrm{w}}=$ $338 \mathrm{~g} / \mathrm{mol}$ ), 1,3-bis(hydroxypropyl)-1,1,3,3-tetramethyl disiloxane (SIPOL, $M_{\mathrm{w}}=250 \mathrm{~g} / \mathrm{mol}$ ), and 1,3-bis(hydroxymethyl)-1,1,3,3-tetramethyl disiloxane (SIMOL, $M_{\mathrm{w}}=194 \mathrm{~g} / \mathrm{mol}$ ) as chain extenders (Figure 1), which showed good thermal stability and good mechanical properties. Synthesizing PSiUs of the possible highest tensile strength and of over 30\% siloxane content was another objective of our work as previously ultimate tensile strength of only maximum $23 \mathrm{MPa}$ was reported in siloxanepolyurethanes of high siloxane content $[11,12,15]$, however, some applications require higher tensile strength (e.g. timing belts). We aimed to reveal the usability of the aforementioned disiloxanes in practice, thus we reacted them with a widely used diisocyanate monomer and used easily implementable techniques.

The tensile strength of all the samples was measured. Isothermal thermogravimetric analyses at 120 and $170^{\circ} \mathrm{C}$ for 230 hours were carried out on a set of samples of the best tensile strength which were synthesized by applying similar compositions. At the same time the changes in hardness and tensile strength were followed. TGA was carried out on the same set of the samples to investigate the effect of the chain extenders on thermal degradation, and also the effect of the PSi content was studied. More flexible polymers of high PSi content and moderate cross-link density were analysed by DMTA and by swelling measurements in THF. The average molecular weight between the cross-links $\left(M_{\mathrm{c}}\right)$ was determined by swelling measurements. The correlations 
between $M_{\mathrm{cs}}, T_{\mathrm{gs}}$, PSi content, chain extenders and tensile strength were investigated.

\section{Experimental section}

\subsection{Materials}

1,4-butanediol (BDO) was purchased from Merck, Germany (>99\%). Lupranol-1301 and Lupranol1100 are products of BASF, Germany. Lupranol1301 is a trifunctional polyether polyol with secondary $\mathrm{OH}$ groups $\left(M_{\mathrm{w}}=430 \mathrm{~g} / \mathrm{mol}\right)$; and Lupranol-1100 is a difunctional polypropylene glycol $\left(M_{\mathrm{w}}=1100 \mathrm{~g} / \mathrm{mol}\right) . \alpha, \omega$-hydroxyethoxyethyl polydimethylsiloxane (SLM-446060-15, $M_{\mathrm{w}}=700 \mathrm{~g} / \mathrm{mol}$, henceforth abbreviated as SLM) was purchased from Wacker Chemie GmbH, Germany. All the aforementioned hydroxy functional compounds were dried under vacuum before use. A mixture of 2,4'- and 4,4'-methylene diphenyl diisocyanate (in $52: 48$ ratio, respectively, $M_{\mathrm{w}}=250 \mathrm{~g} / \mathrm{mol}$ ), called Lupranat MI was obtained from BASF, Germany and it was used as received. Butyl acetate was purchased from Molar Chemicals Kft., Hungary ( $>99 \%$ ), dried over molecular sieves and distilled before using. THF was purchased from Merck, Germany $(>99 \%)$ and it was used as received. All disiloxane chain extenders were synthesized in our laboratory according to the methods published recently [20].

\subsection{Polymer synthesis}

PSiUs were synthesized in a two-step polymerization in butyl acetate solution without catalysts. Our standard procedure is described below and the compositions are listed in Table 1. All the compounds except for the chain extenders were mixed in a round bottom flask under nitrogen and they were stirred for a couple of minutes at $115^{\circ} \mathrm{C}$. As the mixture became viscous and the reaction started, butyl acetate was added to get a $25 \mathrm{w} / \mathrm{w} \%$ diluted solution. After one hour reaction the chain extender was added to the solution and it was reacted for 1015 minutes. Then the solutions were poured into flat sample holders and dried in normal ambinent conditions at room temperature for one day. All the samples were annealed at $60^{\circ} \mathrm{C}$ for two hours and then at $120^{\circ} \mathrm{C}$ for 4 hours. Every sample was prepared in 5-10 g scale. The resulting sheets were $1 \pm 0.1 \mathrm{~mm}$ thick except for the samples made for shock resistance (SR). $30 \pm 5 \mu \mathrm{m}$ films were made on aluminum plates for SR. The plates were cleaned in iso-propyl alcohol before using, so the adhesion of the coatings was defect-free. The general scheme of the polymer structure is depicted in Figure 2.

\subsection{Characterization methods and equipment}

Mechanical testing was carried out on $4 \mathrm{~mm}$ dumbbell shaped test samples at room temperature by a Heckert ZMGi 250 machine (VEB Thüringer Industrialwerk, Ravenstein DDR, digitalized later on). A $1 \mathrm{kN}$ load cell was used and the crosshead speed was $250 \mathrm{~mm} / \mathrm{min}$ (MSZ 490-74 standard). The hardness of the samples was determined by a Bareiss HPE II-A - Shore A digital durometer hardness

Table 1. Composition (in mol) of the polymer samples made of the cross-linker (Lupranol-1301), the chain extenders (CE), the poly(dimethylsiloxane) (SLM), MDI, and weight percentage of the dimethyl siloxane content in the polymer composition

\begin{tabular}{|c|c|c|c|c|c|c|c|}
\hline Sample name & $\begin{array}{c}\text { Lupranol-1301 } \\
\text { [mol] }\end{array}$ & $\begin{array}{c}\mathbf{C E} \\
{[\mathrm{mol}]}\end{array}$ & $\begin{array}{l}\text { SLM } \\
{[\mathrm{mol}]}\end{array}$ & $\begin{array}{l}\text { MDI } \\
{[\mathrm{mol}]}\end{array}$ & $\begin{array}{c}\mathrm{w} / \mathrm{w} \% \text { of }\left[\mathrm{Me}_{2} \mathrm{SiO}\right] \\
{[\%]}\end{array}$ & $\begin{array}{c}w / w \% \text { of } \\
\text { disiloxane CE }\end{array}$ & $\begin{array}{c}\text { w/w\% of } \\
\text { polysiloxane }\end{array}$ \\
\hline $\mathrm{PU}$ & 1.4 & 0 & $1.1^{*}$ & 3.3 & 0 & 0 & 0 \\
\hline PU-SIMOL & 1 & 2 & 0 & 3.85 & 16.6 & 22 & 0 \\
\hline PU-SIPOL & 1 & 2 & 0 & 3.85 & 15.6 & 26 & 0 \\
\hline PU-SILOL & 1 & 2 & 0 & 3.85 & 14.3 & 33 & 0 \\
\hline PU-SIPA & 1 & 2 & 0 & 3.85 & 13.1 & 33 & 0 \\
\hline PU-SIKOL & 1 & 2 & 0 & 3.85 & 13.2 & 38 & 0 \\
\hline PU-BDO-SLM & 0.2 & 2 & 0.9 & 3.6 & 24.6 & 0 & 39 \\
\hline PU-SIMOL-SLM & 0.2 & 2 & 0.9 & 3.6 & 36.2 & 19 & 31 \\
\hline PU-SIPA-SLM & 0.2 & 2 & 0.9 & 3.6 & 31.9 & 29 & 27 \\
\hline PU-SIKOL-SLM & 0.2 & 2 & 0.9 & 3.6 & 29.8 & 34 & 26 \\
\hline PU-SILOL-SLM1 & 1 & 2 & 0.25 & 4.15 & 18.4 & 29 & 8 \\
\hline PU-SILOL-SLM2 & 1 & 2 & 1 & 5 & 26.6 & 22 & 23 \\
\hline PU-SILOL-SLM & 0.2 & 2 & 0.9 & 3.6 & 31.9 & 29 & 27 \\
\hline PU-SIPOL-SLM1 & 1 & 2 & 0.25 & 4.15 & 19.9 & 23 & 8 \\
\hline PU-SIPOL-SLM2 & 1 & 2 & 1 & 5 & 28.3 & 17 & 24 \\
\hline PU-SIPOL-SLM & 0.2 & 2 & 0.9 & 3.6 & 34.4 & 24 & 30 \\
\hline
\end{tabular}

*instead of SLM, Lupranol-1100 was added 


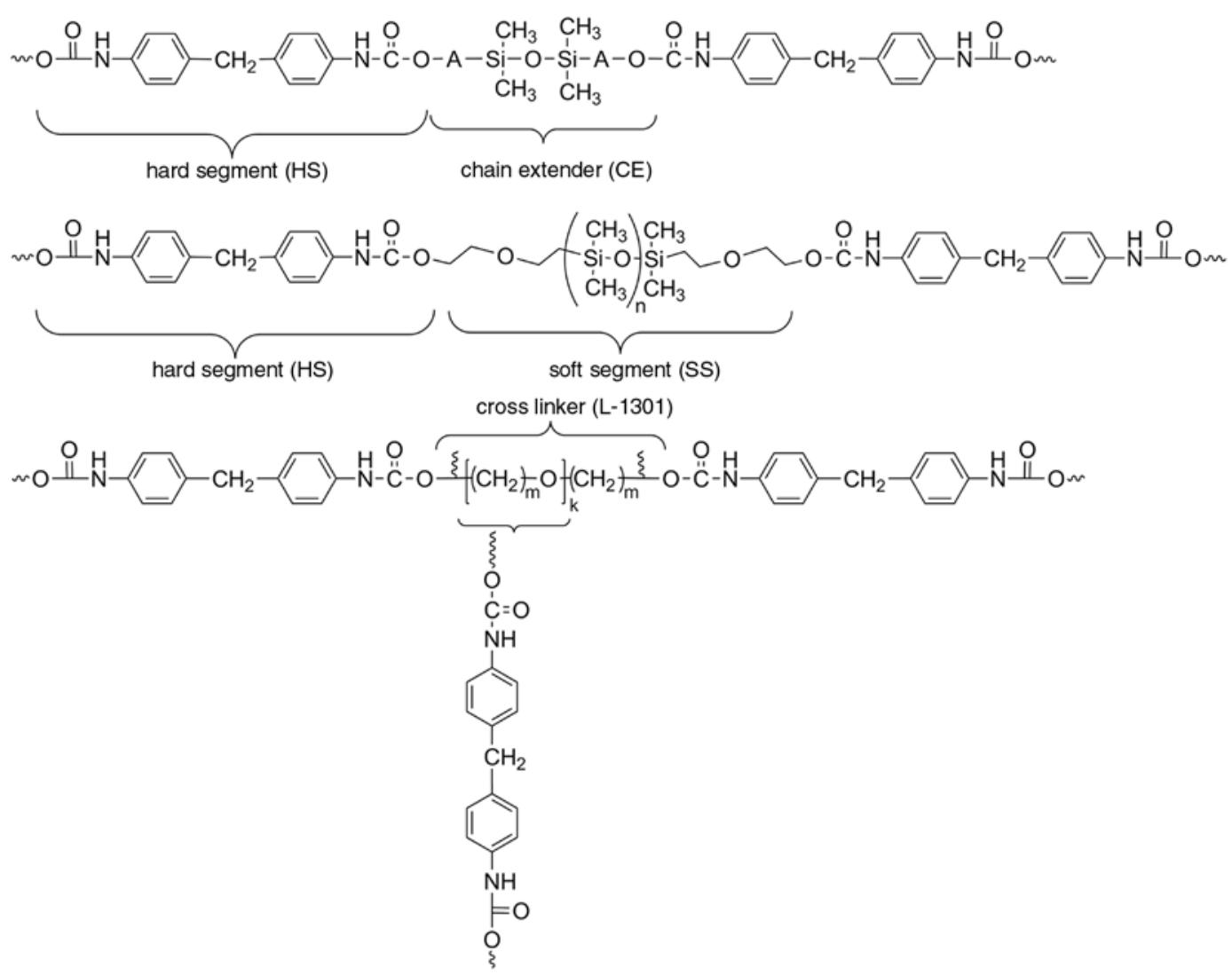

Figure 2. General schemes of the prepared PSiUs, $\mathrm{A}=\left(\mathrm{CH}_{2}\right)_{5}-\mathrm{COO}-\mathrm{CH}_{2},\left(\mathrm{CH}_{2}\right)_{2}-\mathrm{O}-\left(\mathrm{CH}_{2}\right)_{3}, \mathrm{CH}\left(\mathrm{CH}_{3}\right)-\mathrm{COO}_{-}-\mathrm{CH}_{2}, \mathrm{C}_{3} \mathrm{H}_{6}$, $\mathrm{CH}_{2}$

tester (Bareiss Prüfgeratebau GMbH, Oberdischingen, Germany) (DIN 53505 standard). The shock resistance was tested on aluminum plates with a 500g-hammer (Labor-MIM, Hungary) dropped from $50 \mathrm{~cm}$.

A Binder FD115, (Binder GMbH Tuttlingen, Germany) air-circulating laboratory oven was used for the isothermal thermogravimetric analysis. Numerous dumb-bell shaped samples and also discs of $1 \pm 0.1 \mathrm{~g}$ were placed in the oven at 120 or $170^{\circ} \mathrm{C}$. Five replicates of each polymer composition were taken at one time for tensile strength and hardness measurements, and the discs were weighed and placed back into the oven for further tempering. The results represent the median values of the replicates. All these measurements were carried out after cooling down the samples to room temperature.

TGA was performed by using MOM Derivatograph Q-1500, Hungary (equipped with Derill-X digital system, the data processing was performed on Winder software) at a heating rate of $5^{\circ} \mathrm{C} / \mathrm{min}$ under nitrogen or in air. The sample weights were $105 \pm 5 \mathrm{mg}$. A Perkin Elmer Diamond, Perkin Elmer Instruments, Japan was used for DMTA measurements. All the test samples were heated at a heating rate of $2^{\circ} \mathrm{C} / \mathrm{min}$ from -150 to $200^{\circ} \mathrm{C}$ at a $1 \mathrm{~Hz}$ frequency setting.

The density of the investigated PSiU polymers was determined by using a pycnometer and water at room temperature.

The swelling measurements were carried out at room temperature in THF solvent. All the samples were immersed in THF until their mass changed $\left(m_{\mathrm{s}}\right)$; then they were dried in normal air conditions at room temperature until constant mass was obtained $\left(m_{\mathrm{d}}\right)$.

\section{Results and discussion}

Every sample was clear, transparent and slightly yellow. The polymer compositions are listed in Table 1. The names of the compositions indicate the applied chain extender (CE) and whether they contained the polysiloxane diol (SLM) or not. PU sample contained Lupranol-1100, because the pure BDO/Lupranol-1301/MDI blend was brittle, so we formulated a pure organic polyurethane composition in order to obtain a polymer of similar mechanical properties like the other samples with siloxane chain extenders and without polysiloxane. 
Our aim was to investigate our samples from a practical point of view, thus we let them dry under normal ambient conditions and we annealed them in air. To prevent the polymers from the negative impact of air humidity we applied $10 \%$ excess of isocyanates in each sample. Reacting with water the excess isocyanates form urea, so PUs can be protected or even improved.

\subsection{Tensile strength and hardness}

The tensile strength (UTS), the elongation at break, the Shore A hardness and the shock resistance (SR) of the polymers are listed in Table 2 . Though these materials are very tough, all the samples (of $1 \mathrm{~mm}$ thickness) even the ones of negative shock resistance could be bended back by $180^{\circ}$ without any damage. From these results it is evident that the structure of the chain extenders has a strong effect on the final physical properties. The chain extenders of higher molecular weight have more flexibility and provide moderate hardness and smaller tensile strength. At constant molar ratio of the polysiloxane the chain length of the disiloxane determines the tensile strength. The chain length of the chain extenders is reflected in their weight percentage as the molar ratios were constant in each group of the compositions (Table 1). Thus the effect of the different chain extenders with or without polysiloxane can be compared as depicted in Figure 3. UTS decreases by increasing the chain length except for SIPOL. In both series, regardless of the presence of SLM, samples containing SIPOL, despite its longer

Table 2.The mechanical properties of the synthesized polymers

\begin{tabular}{|l|c|c|c|c|}
\hline \multicolumn{1}{|c|}{ Sample name } & $\begin{array}{c}\text { UTS } \\
{[\mathbf{M P a}]}\end{array}$ & $\begin{array}{c}\text { Elongation at } \\
\text { break [\%] }\end{array}$ & Shore A & SR \\
\hline PU & 35.6 & 6.1 & 77 & + \\
\hline PU-SIMOL & 64.2 & 8.6 & 92 & + \\
\hline PU-SIPOL & 66.5 & 6.9 & 91 & + \\
\hline PU-SILOL & 50.4 & 5.7 & 92 & - \\
\hline PU-SIPA & 33.2 & 10.0 & 69 & - \\
\hline PU-SIKOL & 29.9 & 10.7 & 79 & + \\
\hline PU-BDO-SLM & 41.8 & 14 & 68 & + \\
\hline PU-SIMOL-SLM & 32.3 & 12 & 75 & + \\
\hline PU-SIPA-SLM & 16.0 & 111 & 60 & + \\
\hline PU-SIKOL-SLM & 13.9 & 192 & 67 & + \\
\hline PU-SILOL-SLM1 & 54.0 & 12 & 89 & + \\
\hline PU-SILOL-SLM2 & 33.9 & 14 & 85 & + \\
\hline PU-SILOL-SLM & 25.3 & 15 & 81 & + \\
\hline PU-SIPOL-SLM1 & 56.2 & 10 & 87 & + \\
\hline PU-SIPOL-SLM2 & 34.6 & 14 & 82 & + \\
\hline PU-SIPOL-SLM & 33.5 & 16 & 78 & + \\
\hline
\end{tabular}

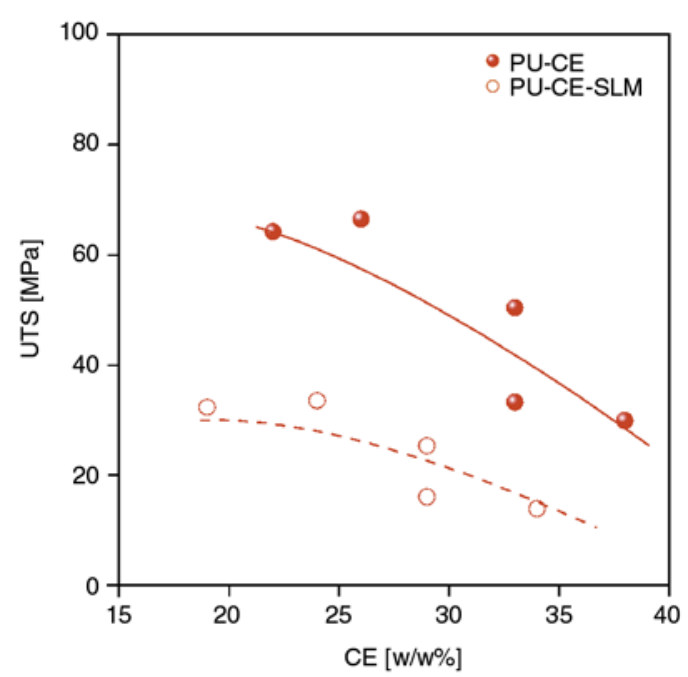

Figure 3. The effect of the different chain extenders (CE) on the ultimate tensile strength (UTS). PU-CESLM: polysiloxane incorporated, PU-CE: no polysiloxane in the samples

chains, had higher UTS than samples containing SIMOL. SILOL and SIPA are the same molecular weight, but SILOL has a branched side-chain, so it is shorter and accordingly it has higher UTS.

Trying to find the difference between bis(hydroxyalkylester) and the other disiloxanes (SIKOLSILOL and SIMOL-SIPA-SIPOL, respectively), we found a less significant correlation between the type of the disiloxane and the tensile strength or the hardness. The chain length and the flexibility are more considerable factors regarding the investigated mechanical properties. Comparing PU-SILOLSLMi variations with PU-SIPOL-SLMi samples, the ones containing SIPOL showed slightly higher tensile strength and less hardness. It indicates that the carboxyl group has no prevalent effect and the chain length determines the final properties, thus SIPOL with shorter chains has higher tensile strength, but the secondary hydroxyl group containing SILOL results in harder polymers (Figure 4a). Increasing the ratio of the polysiloxane compound induces a significant decrease in the tensile strength, the hardness (Figure 4b) and an increase in the elongation. This phenomenon proved our hypothesis: more flexible but less strong materials can be prepared by adding more polysiloxane SS.

Though the chain extenders and the polysiloxane content have a strong impact on the polymer characteristics, in our samples there is no simple linear relation between them and the resulting tensile strength or other physical properties. The structure of the chain extender has a strong effect on the 

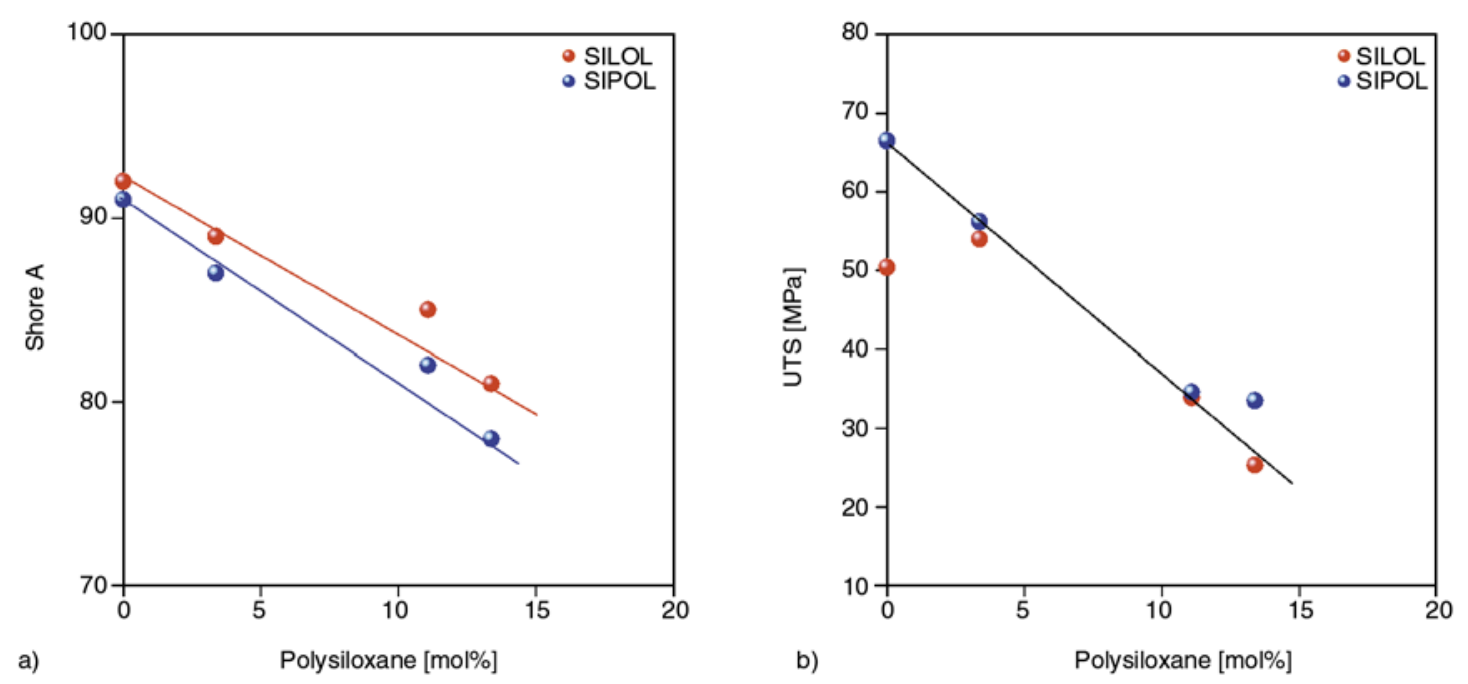

Figure 4. Shore A hardness (a) and UTS (b) in the function of the polysiloxane content when SILOL or SIPOL chain extenders were used

physical properties of the polymers and it determines dominantly the final characteristics together with the crosslink density. Besides, the overall dimethyl siloxane content incorporating the effect of the polysiloxane content and the structure of the disiloxane influence the physical properties as well. The structure of the disiloxanes appears in their weight percentage in the polymer, because their molecular weight increases as their chain length increases at constant molar ratio. Both increasing chain length and the higher polysiloxane content decrease the UTS. So we defined $\mathrm{x}$ as a numerical expression for these two factors (Equation (1)):

$x=\mathrm{w} / \mathrm{w} \%(\mathrm{CE}) \cdot \mathrm{w} / \mathrm{w} \%(\mathrm{PSi})$

In the function of $x$ still no exact equation can be determined, but $x$ combined with the overall siloxane content allows us to fit a trend-plane or a trendline to the represented data as depicted in Fig- ures $5 \mathrm{a}$ and $5 \mathrm{~b}$, the corresponding data are listed in Table 3 (polymers without any disiloxane or polysiloxane are mostly not representative in this comparison). These equations can be useful in designing polymers made of similar compounds.

\subsection{Isothermal thermogravimetric and mechanical analysis}

The thermal stability of a selection of polymers of high UTS was investigated under isothermal conditions at 120 and $170^{\circ} \mathrm{C}$, that can occur occasionally under any working condition where PSiUs might be used. The chosen polymer compositions were made of three compounds in which the ratio of the monomers was constant, only the chain extender was different in each material. The reference sample was a PU of which mechanical properties were similar to the other samples. The tensile strength, the elongation at break and the hardness properties at $120^{\circ} \mathrm{C}$ are listed in the function of time in Table 4,

Table 3. Relationship between the UTS, the overall siloxane content $\left[\mathrm{Me}_{2} \mathrm{SiO}\right]$ [\%], the chain length of the disiloxane chain extenders (incorporated in $\mathrm{CE}[\mathrm{w} / \mathrm{w} \%]$ ), and the polysiloxane content $[\mathrm{w} / \mathrm{w} \%]$

\begin{tabular}{|c|c|c|c|c|}
\hline Sample name & $\begin{array}{c}\text { UTS } \\
{[\mathrm{MPa}]}\end{array}$ & $\begin{array}{c}{\left[\mathrm{Me}_{2} \mathrm{SiO}\right]} \\
{[\%]}\end{array}$ & $x=(C E[w / w \%] \cdot p o l y s i l o x a n e[w / w \%])$ & $\begin{array}{c}\mathrm{x} /\left[\mathrm{Me}_{2} \mathrm{SiO}\right] \\
{[\%]}\end{array}$ \\
\hline PU-SIPOL & 66.5 & 15.6 & 0 & 0 \\
\hline PU-SIPOL-SLM1 & 56.2 & 19.9 & 191 & 9.58 \\
\hline PU-SILOL-SLM1 & 54.0 & 18.4 & 220 & 11.96 \\
\hline PU-SIPOL-SLM2 & 34.6 & 28.3 & 422 & 14.91 \\
\hline PU-SILOL-SLM2 & 33.9 & 26.6 & 507 & 19.05 \\
\hline PU-SIMOL-SLM & 32.3 & 36.2 & 609 & 16.81 \\
\hline PU-SIPOL-SLM & 33.5 & 34.4 & 704 & 20.45 \\
\hline PU-SILOL-SLM & 25.3 & 31.9 & 811 & 25.41 \\
\hline PU-SIPA-SLM & 16.0 & 36.2 & 811 & 22.39 \\
\hline PU-SIKOL-SLM & 13.9 & 29.8 & 879 & 29.48 \\
\hline
\end{tabular}



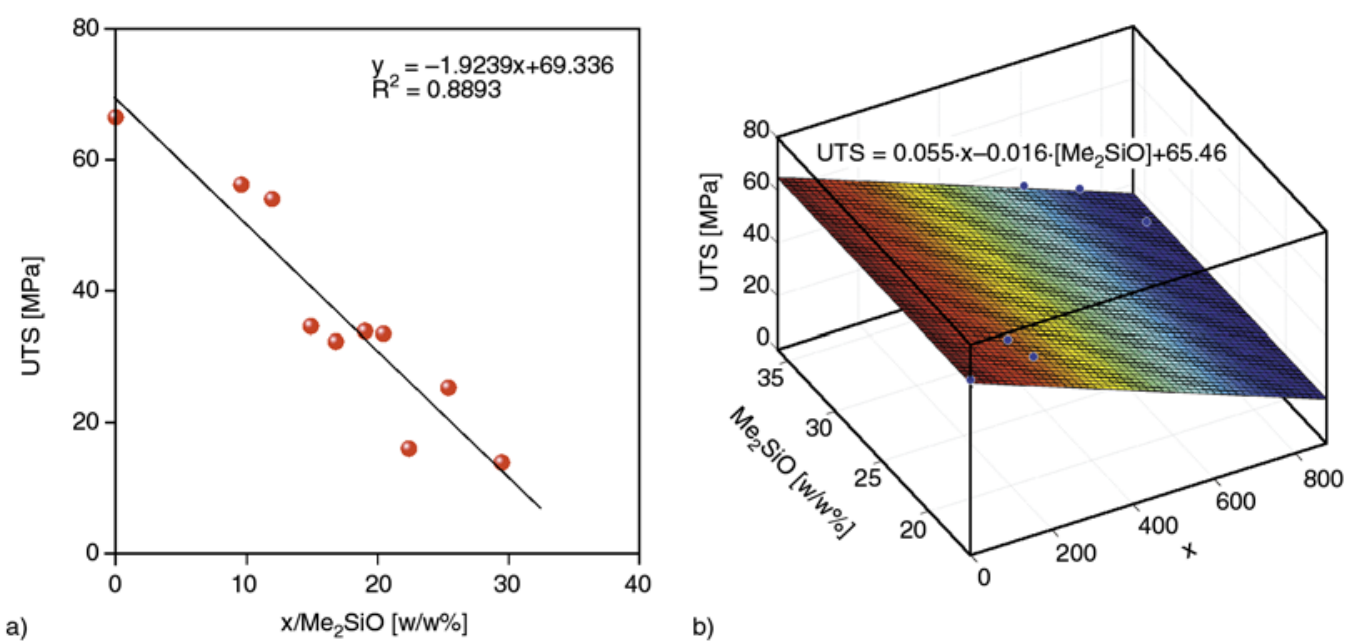

Figure 5. (a) Illustration of the relationship between the combined number made up of the siloxane unit, the chain extender and the polysiloxane content and UTS; (b) 3D diagram illustrating the relationship between the siloxane content, $x$ (the combined number made up of the chain extender and polysiloxane content) and UTS

the results of the study at $170^{\circ} \mathrm{C}$ in Table 5 . The weight losses are represented in Figure 6 and 7.

Significant differences were observed by using diverse chain extenders in these simple compositions. The behaviour of PU-SILOL was very different from that of the other samples; it was decomposed after one day at $170^{\circ} \mathrm{C}$ and became too brittle to measure after two days at $120^{\circ} \mathrm{C}$. This phenomenon can be attributed to the secondary hydroxy groups as they provide less stable urethane bonds [21].

Both chosen temperatures are lower than the decomposition temperature of the urethane bond, which is thermally the least stable bond in PSiU systems [13, 16]. The annealing time and temperature were worked out previously by monitoring tensile strength and hardness changes, and this is why it was interesting that after the first day of tempering relatively big weight loss was observed at both temperatures.

The most stable polymer samples turned out to be PU and PU-SIKOL. They lost 3.3-3.6\% of their mass at $120^{\circ} \mathrm{C}$ and $14.3-14.6 \%$ at $170^{\circ} \mathrm{C}$ until the end of the study. The most degradable materials were PU-SIPA and PU-SIMOL (besides PU-SILOL) which lost $7.6-8.0 \%$ of their weight at $120^{\circ} \mathrm{C}$ and $23.7-26.8 \%$ at $170^{\circ} \mathrm{C}$ within eight days. Most of the

Table 4. Changes in the mechanical properties after tempering a selection of the samples at $120^{\circ} \mathrm{C}$ for a given time (with '-' denoted samples were too brittle to measure)

\begin{tabular}{|c|c|c|c|c|c|c|c|c|c|c|c|c|c|c|c|}
\hline \multirow{2}{*}{$\begin{array}{c}120^{\circ} \mathrm{C} \\
\text { Sample } \backslash \text { Time }[\mathrm{h}]\end{array}$} & \multicolumn{5}{|c|}{ Tensile strength [MPa] } & \multicolumn{5}{|c|}{ Elongation at break [\%] } & \multicolumn{5}{|c|}{ Shore A hardness } \\
\hline & $\mathbf{0}$ & 25 & 50 & 100 & 230 & $\mathbf{0}$ & 25 & 50 & 100 & 230 & $\mathbf{0}$ & 25 & $\mathbf{5 0}$ & 100 & 230 \\
\hline $\mathrm{PU}$ & 35.6 & 35.6 & 31.8 & 31.6 & 32.4 & 6.1 & 6.1 & 0.8 & 2.0 & 13.0 & 77 & 77 & 89 & 89 & 98 \\
\hline PU-SIMOL & 64.2 & 67.5 & 49.9 & 53.3 & 57.7 & 8.6 & 3.4 & 9.7 & 2.5 & 10.3 & 92 & 91 & 96 & 90 & 95 \\
\hline PU-SIPOL & 66.5 & 49.6 & 63.5 & 52.9 & 68.5 & 6.9 & 0.3 & 8.0 & 7.9 & 7.5 & 91 & 87 & 98 & 98 & 97 \\
\hline PU-SILOL & 50.4 & 54.1 & - & - & - & 5.7 & 12.0 & - & - & - & 92 & 94 & 96 & 100 & 100 \\
\hline PU-SIPA & 33.2 & 49.5 & 45.1 & 46.6 & 47.1 & 10.0 & 9.0 & 10.0 & 0.3 & 7.0 & 69 & 90 & 87 & 96 & 99 \\
\hline PU-SIKOL & 29.9 & 32.2 & 41.8 & 40.7 & 32.8 & \begin{tabular}{|l|}
10.7 \\
\end{tabular} & 2.8 & 6.5 & 10.5 & 7.0 & 79 & 80 & 99 & 91 & 88 \\
\hline
\end{tabular}

Table 5. Changes in the mechanical properties after tempering a selection of the samples at $170^{\circ} \mathrm{C}$ for a given time (with '-' denoted samples were decomposed in the oven)

\begin{tabular}{|c|c|c|c|c|c|c|c|c|c|c|c|c|c|c|c|}
\hline \multirow{2}{*}{$\begin{array}{c}170^{\circ} \mathrm{C} \\
\text { Sample } \backslash \text { Time }[\mathrm{h}]\end{array}$} & \multicolumn{5}{|c|}{ Tensile strength [MPa] } & \multicolumn{5}{|c|}{ Elongation at break [\%] } & \multicolumn{5}{|c|}{ Shore A hardness } \\
\hline & $\mathbf{0}$ & 25 & 50 & 100 & 200 & $\mathbf{0}$ & 25 & $\mathbf{5 0}$ & 100 & 200 & $\mathbf{0}$ & 25 & $\mathbf{5 0}$ & 100 & 200 \\
\hline PU & 35.6 & 28.8 & 20.2 & 22.2 & 31.6 & 6.1 & 8.4 & 7.6 & 10.0 & 9.8 & 77 & 93 & 93 & 95 & 94 \\
\hline PU-SIMOL & 64.2 & 60.9 & 37.0 & 54.5 & 30.9 & 8.6 & 6.7 & 5.5 & 5.2 & 6.6 & 92 & 99 & 100 & 95 & 100 \\
\hline PU-SIPOL & 66.5 & 56.5 & 47.6 & 73.6 & 32.4 & 6.9 & 14.0 & 3.7 & 6.2 & 0.3 & 91 & 96 & 97 & 93 & 100 \\
\hline PU-SILOL & 50.4 & - & - & - & - & 5.7 & - & - & - & - & 92 & - & - & - & - \\
\hline \begin{tabular}{|l|} 
PU-SIPA \\
\end{tabular} & 33.2 & 43.6 & 45.4 & 59.9 & 42.4 & 10.0 & 3.7 & 6.6 & 6.0 & 3.6 & 69 & 87 & 91 & 93 & 100 \\
\hline \begin{tabular}{|l} 
PU-SIKOL \\
\end{tabular} & 29.9 & 33.7 & 26.4 & 29.7 & 43.5 & 10.7 & 6.1 & 9.0 & 6.1 & 9.5 & 79 & 85 & 95 & 93 & 100 \\
\hline
\end{tabular}




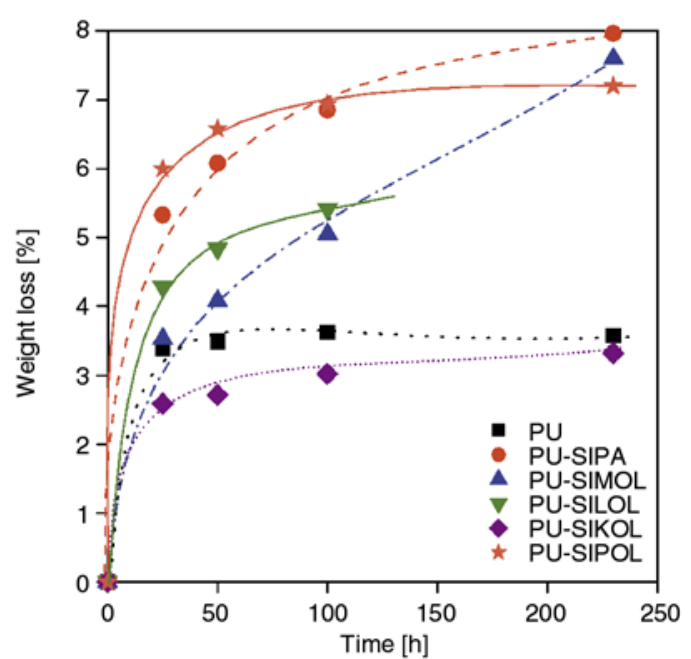

Figure 6. Weight loss (in percentage) of a selection of the samples over time at $120^{\circ} \mathrm{C}$

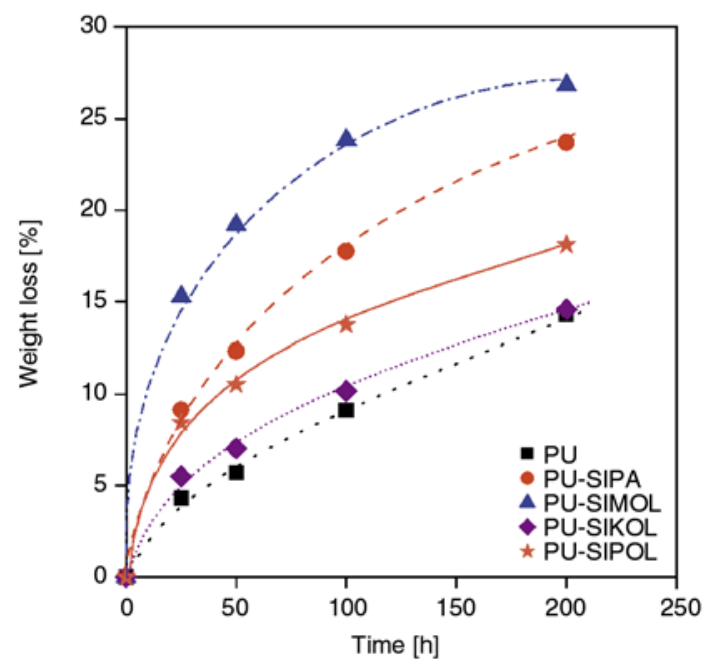

Figure 7. Weight loss (in percentage) of a selection of the samples over time at $170^{\circ} \mathrm{C}$

weight loss was observed on the first day at $120^{\circ} \mathrm{C}$ annealing temperature. During the following eight days further decrease up to $4.1 \%$ was measured at any sample, at PU-SIKOL it was only $0.7 \%$, at PU it was $0.2 \%$.

At $170^{\circ} \mathrm{C}$ the first day was also exceptional, but the following week resulted in a significant weight loss as well. After one day PU lost 4.3\%, PU-SIKOL 5.5\% and PU-SIMOL $15.3 \%$ of their weight. The following week the order of the additional weight losses changed: PU-SIKOL $(9.1 \%)>$ PU-SIPOL $(9.7 \%)>$ PU $(10.0 \%)>$ PU-SIMOL (11.5\%) > PU-SIPA $(14.6 \%)$. The significantly bigger weight loss of the first day can be explained by the evaporation of the volatile compounds such as residual solvent traces and cyclic siloxane oligomers [18].
The longer time the samples were in the oven, the harder, and the darker they became, for example they got even dark brown and some of them got brittle at $170^{\circ} \mathrm{C}$. Although the hardness increased explicitly in accordance with the tempering time, the tensile strength values do not follow a monotonous trend line (Tables 4 and 5). The least fluctuation in UTS was observed at PU and PU-SIKOL. These phenomena can be the result of a slow postpolymerization combined with a moderate degradation process. Post-polymerization means a very complex process as we applied an excess of diisocyanate and a high cross-link density. First of all the reaction between the cross-linker and the diisocyanate can be completed during isothermal annealing. Furthermore, the residual isocyanate can react with another neighbouring urethane group forming an allophanate cross-link. It can also react with water from the air resulting in urea first, and if it reacts with another isocyanate group in biuret cross-linking [22].

The isothermal thermogravimetric and mechanical analysis revealed that except for PU-SILOL all samples especially PU and PU-SIKOL have good thermal stability which is reflected in relatively small weight loss and changes in hardness and tensile strength.

\subsection{Thermogravimetric analysis (TGA)}

A selection of the polymers was analysed under nitrogen and in air by using TGA. The effects of different chain extenders and different polysiloxane contents were studied. TGA data are listed in Tables 6 and 7. The effect of the increasing amount of polysiloxane is shown in Figure 8.

According to the thermogravimetric (TG) and derivative thermogravimetric (DTG) curves at least two but in most cases three degradation steps can be distinguished. Not all the degradation steps go through an inflection point; in some regions the residual weight decreases linearly with the growing temperature. All the degradation steps correlate with the reports published previously.

Comparing the selected data listed in Tables 6 and 7 , the degradation steps on the TG curves in most cases start at higher temperatures under nitrogen than in air. The initial degradation in air started between $220-260^{\circ} \mathrm{C}$, while under nitrogen between $230-275^{\circ} \mathrm{C}$; and it was revealed that first urethane 
Table 6. TGA data recorded in air. T1, T2, T3 designate the first, second, and third degradation steps respectively. To all steps onset (on), DTG minimum (mid), and offset (off) points are given.

\begin{tabular}{|l|c|c|c|c|c|c|}
\hline \multirow{2}{*}{ Sample name } & \multicolumn{7}{|c|}{ Typical temperature $\left.{ }^{\circ} \mathbf{C}\right]$} \\
\cline { 2 - 7 } & T1 on/mid/off & T2 on/mid/ off & T3 on/ mid/off & at 10\% weight loss & at 50\% weight loss & at 80\% weight loss \\
\hline PU & $260 / 362 / 420$ & - & $420 / 587 / 647$ & 330 & 364 & 460 \\
\hline PU-SIMOL & $219 / 316 / 393$ & $393 / 400 / 478$ & $478 / 568 / 640$ & 314 & 369 & 525 \\
\hline PU-SIPOL & $255 / 310 / 495$ & - & $495 / 595 / 645$ & 297 & 339 & 509 \\
\hline PU-SILOL & $252 / 274 / 287$ & $287 / 332 / 478$ & $478 / 563 / 650$ & 294 & 383 & 454 \\
\hline PU-SIPA & $240 / 296 / 320$ & $320 / 358 / 540$ & $540 / 622 / 659$ & 297 & 375 & 465 \\
\hline PU-SIKOL & $267 / 328 / 392$ & $392 / 414 / 492$ & $492 / 572 / 620$ & 268 & 400 & 495 \\
\hline PU-SILOL-SLM1 & $222 / 303 / 323$ & $323 / 348 / 442$ & $442 / 592 / 634$ & 283 & 346 & 492 \\
\hline PU-SILOL-SLM2 & $235 / 341 / 466$ & - & $466 / 588 / 660$ & 300 & 362 & 532 \\
\hline PU-SIPOL-SLM1 & $246 / 312 / 386$ & $386-540$ & $540 / 620 / 710$ & 298 & 368 & 496 \\
\hline PU-SIPOL-SLM2 & $242 / 297 / 322$ & $322 / 332 / 370$ & $570 / 627 / 695$ & 258 & 334 & 524 \\
\hline
\end{tabular}

Table 7. TGA data recorded in nitrogen. T1, T2, T3 designate the first, second, and third degradation steps respectively. To all steps onset (on), DTG minimum (mid), and offset (off) points are given.

\begin{tabular}{|l|c|c|c|c|c|c|}
\hline \multirow{2}{*}{ Sample name } & \multicolumn{7}{|c|}{ Typical temperature ${ }^{\circ} \mathbf{C}$ ] } \\
\cline { 2 - 7 } & T1 on/mid/off & T2 on/mid/ off & T3 on/ mid/off & at 10\% weight loss & at 50\% weight loss & at 80\% weight loss \\
\hline PU & $264 / 362 / 420$ & - & $420-760$ linear & 323 & 369 & 410 \\
\hline PU-SIMOL & $230 / 275 / 288$ & $288 / 338 / 520$ & $520-900$ linear & 300 & 380 & 467 \\
\hline PU-SIPOL & $253 / 314 / 325$ & $325 / 336 / 401$ & $401-885$ linear & 337 & 357 & 397 \\
\hline PU-SILOL & $246 / 330 / 350$ & $350 / 399 / 456$ & $456-900$ linear & 355 & 408 & 442 \\
\hline PU-SIPA & $271 / 363 / 408$ & - & $408-600$ linear & 337 & 371 & 437 \\
\hline PU-SIKOL & $275 / 346 / 373$ & $373 / 417 / 490$ & $490-816$ linear & 317 & 395 & 448 \\
\hline PU-SILOL-SLM1 & $253 / 337 / 378$ & $378 / 423 / 500$ & $500 / 584 / 640$ & 267 & 395 & 451 \\
\hline PU-SILOL-SLM2 & $227 / 389 / 460$ & - & $460 / 540 / 668$ & 290 & 394 & 534 \\
\hline PU-SIPOL-SLM1 & $239 / 300 / 510$ & - & $510-900$ linear & 247 & 347 & 477 \\
\hline PU-SIPOL-SLM2 & $240 / 295 / 358$ & $358 / 420 / 468$ & $468 / 596 / 640$ & 253 & 412 & 463 \\
\hline
\end{tabular}

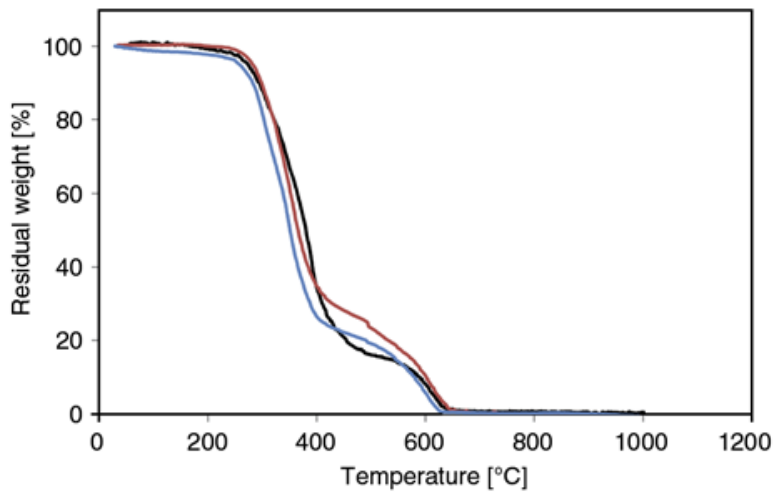

Figure 8. TG curves of PU-SILOL (black), PU-SILOLSLM1 (blue), and PU-SILOL-SLM2 (red) recorded in air

bonds degrade causing depolymerization, and it is followed by the loss of the volatile compounds [13, $14,16,17]$. The relatively high onset temperature in the case of PU might indicate the effect of the crosslinks. Using disiloxane chain extenders the initial degradation step was generally shifted to lower temperatures except for PU-SIKOL. As urethane bonds are the least thermally stable in these systems, it is hard to improve the thermal stability of the polyurethanes with siloxane compounds. On the other hand, the TGA characteristics strongly depend on the used chain extender and on the polysiloxane content. First of all, the simple two-step degradation of PU recorded in air usually splits into three well distinguishable regions which are less distinct under nitrogen. The second stage ranges roughly between $300-500^{\circ} \mathrm{C}$ and it corresponds to the degradation of the soft segments. The third step that is above $400^{\circ} \mathrm{C}$ belongs to the decomposition of macrocyclic siloxanes and aromatic compounds. The onset temperature of the third degradation step is occasionally lower under nitrogen than under air, but the offset temperature is significantly higher in nitrogen (up to $900^{\circ} \mathrm{C}$, while in air weight losses reach their maximum at max. $710^{\circ} \mathrm{C}$ ). Also, the weight loss in nitrogen is mostly linear in the function of temperature.

Figure 8 depicts the effect of polysiloxane content when SILOL chain extender is applied. The onset temperatures differ already in favour of higher polysiloxane content, but then between $350-380^{\circ} \mathrm{C}$ PUSILOL is the least decomposing and above $400^{\circ} \mathrm{C}$ 
PU-SILOL-SLM2 is significantly more stable than the other two samples.

The good thermal stability of the siloxane compounds revealed itself in the last two degradation steps. $50-80 \%$ weight loss occurred at significantly higher temperatures in air in the case of siloxane containing polymers than at PU. It was not true under nitrogen in all cases, and also increasing polysiloxane content not necessarily meant slower weight loss. The reason might be the complex structure of the PSiU networks owing to the secondary hydrogen bonds, segment miscibility, HS/SS ratio, etc. If the results of the same samples analysed in air are compared with the ones studied under nitrogen, the following trends can be observed: $50 \%$ weight loss is reached under nitrogen at higher temperatures usually, but almost all samples lose $80 \%$ of their weight at lower temperatures under nitrogen than in air. These differences show that also thermo-oxidative degradation takes place above $400^{\circ} \mathrm{C}$ in air. During the oxidation of siloxanes nonvolatile silicon-dioxide is formed, thus the measurable weight loss in air is less than under nitrogen.

\subsection{Dynamic mechanical thermal analysis} (DMTA)

A selection of polymers was investigated by DMTA. $T_{\mathrm{g}}$-s of the samples were determined from $E^{\prime \prime}$ and $\tan \delta$ peaks. On set, maximum and end set points of the peaks are listed in Table 8 .

$T_{\mathrm{g} 1}$ refers to the glass transition temperature of the soft segment which is in our study a polysiloxane diol (SLM). The peak belonging to $T_{\mathrm{g} 2}$ is usually very moderate if present at all. It might indicate another phase formed mostly by Lupranol-1301 or an interphase between HS and SS. $T_{\mathrm{g} 3}$ represents the glass transition temperature of the HS and it is the highest peak on $\tan \delta$ and loss modulus $\left(E^{\prime \prime}\right)$ curves as well. All the peaks are the most intense on the loss modulus curves, thus these diagrams are shown.

The difference between the various chain extenders is illustrated in Figure 9. It is obvious that the properties determined by DMTA depend on the applied chain extender in accordance with the mechanical properties. Comparing $T_{\mathrm{g} 1} \mathrm{~S}$ of the soft segments no significant difference was found. This shows that $T_{\mathrm{g} 1}$ of the polysiloxane chains is irrespective of the applied chain extender. All the other chain extenders lower $T_{\mathrm{g} 2}$ and $T_{\mathrm{g} 3}$ and PU-SIKOL-SLM has the lowest values. This indicates that the HS structure is changed but the polysiloxane remains mostly phase separated. The outstanding behaviour of SIKOL can be explained with its long organic chains as SIKOL is the longest one among the investigated chain extenders. Figure $9 \mathrm{~b}$ represents the effect of the chain extenders' length on the determined $T_{\mathrm{g} 3}$ values. These data also indicate that applying a disiloxane containing ether or ester bonds does not make significant difference; the chain length of the chain extenders is more dominant.

PU-BDO-SLM compared to the polymers containing a disiloxane chain extender has lower $T_{\mathrm{g} 3}$ values, which refers to more flexible hard segments than it could be expected. The structure of the hard segments is mostly responsible for the tensile properties [8] and it is reflected in our data as well. If we follow the order of $T_{\mathrm{g} 3} \mathrm{~S}$ depicted in Figure $9 \mathrm{~b}$ and the order of tensile strengths of the same polymers (Figure 3), the two orders are almost the same. Only

Table 8. Glass transition temperatures $\left(T_{\mathrm{g}}\right)$ of a selection of polymers according to $\tan \delta$ and $E^{\prime \prime}$ data

\begin{tabular}{|c|c|c|c|c|c|c|}
\hline \multirow{3}{*}{ Sample name } & \multicolumn{6}{|c|}{ Typical temperature $\left[{ }^{\circ} \mathrm{C}\right]$} \\
\hline & \multicolumn{3}{|c|}{$\tan \delta$} & \multicolumn{3}{|c|}{$\mathbf{E}^{\prime \prime}$} \\
\hline & $T_{g 1}$ on $/ \mathrm{mid} / \mathrm{off}$ & $T_{\mathrm{g} 2}$ on $/ \mathrm{mid} /$ off & $T_{g 3}$ on $/ \mathrm{mid} / \mathrm{off}$ & $T_{g 1}$ on $/ \mathrm{mid} /$ off & $T_{\mathrm{g} 2}$ on $/ \mathrm{mid} /$ off & $T_{g 3}$ on $/ \mathrm{mid} / \mathrm{off}$ \\
\hline PU-BDO-SLM & $-149 /-107 /-54$ & $-54 /-13 / 30$ & $30 / 121 / 176$ & $-149 /-115 /-54$ & $-54 /-18 / 32$ & $32 / \mathbf{9 5} / 190$ \\
\hline PU-SIMOL-SLM & $-147 /-\mathbf{1 0 5} /-63$ & $-62 /-\mathbf{2 3} / 15$ & $15 / 74 / 148$ & $-147 /-\mathbf{1 1 3} /-62$ & $-62 /-\mathbf{2 3} / 17$ & $17 / \mathbf{5 0} / 172$ \\
\hline PU-SIPA-SLM & $-145 /-\mathbf{1 0 5} /-64$ & $-64 /-25 /-4$ & $-4 / \mathbf{5 7} / 136$ & $-145 /-113 /-62$ & $-50 /-26 /-1$ & $-1 / 24 / 130$ \\
\hline PU-SIKOL-SLM & $-135 /-99 /-74$ & $-74 /-\mathbf{5 0} /-21$ & $-21 / 43 / 133$ & $-133 /-\mathbf{1 1 3} /-71$ & $-71 /-\mathbf{5 4} /-17$ & $-17 / \mathbf{1 2} / 127$ \\
\hline PU-SILOL & $-140 /-92 /-41$ & $-41 /-10 / 41$ & $41 / 78 / 138$ & $-140 /-93 /-39$ & $-39 / \mathbf{1} / 44$ & $44 / 69 / 130$ \\
\hline PU-SILOL-SLM1 & $-141 /-93 /-55$ & $-55 /-11 / 15$ & $15 / 75 / 145$ & $-142 /-97 /-52$ & $-52 /-14 / 25$ & $25 / \mathbf{5 2} / 140$ \\
\hline PU-SILOL-SLM2 & $-145 /-\mathbf{1 0 5} /-54$ & $-54 /-19 /-10$ & $-10 / 71 / 143$ & $-145 /-117 /-53$ & $-53 /-10 / 16$ & $16 / 53 / 135$ \\
\hline PU-SILOL-SLM & $-145 /-107 /-52$ & - & $-52 / 68 / 150$ & $-142 /-\mathbf{1 1 5} /-54$ & - & $-54 / 39 / 150$ \\
\hline PU-SIPOL & $-120 /-92 /-54$ & $-54 /-16 / 36$ & $36 / 74 / 113$ & $-115 /-92 /-54$ & $-54 /-17 / 38$ & $38 / \mathbf{6 5} / 111$ \\
\hline PU-SIPOL-SLM1 & $-142 /-\mathbf{9 3} /-50$ & $-50 /-18 / 25$ & $25 / 69 / 148$ & $-142 /-93 /-52$ & $-52 /-21 / 31$ & $31 / 58 / 139$ \\
\hline PU-SIPOL-SLM2 & $-143 /-\mathbf{1 0 3} /-65$ & $-65 /-24 / 10$ & $10 / 67 / 150$ & $-143 /-\mathbf{1 1 3} /-60$ & $-63 /-24 / 15$ & $15 / \mathbf{5 2} / 144$ \\
\hline PU-SIPOL-SLM & $-147 /-\mathbf{1 0 4} /-57$ & $-57 /-25 / 8$ & $8 / 62 / 134$ & $-142 /-112 /-57$ & $-57 /-25 / 8$ & $8 / 46 / 132$ \\
\hline
\end{tabular}



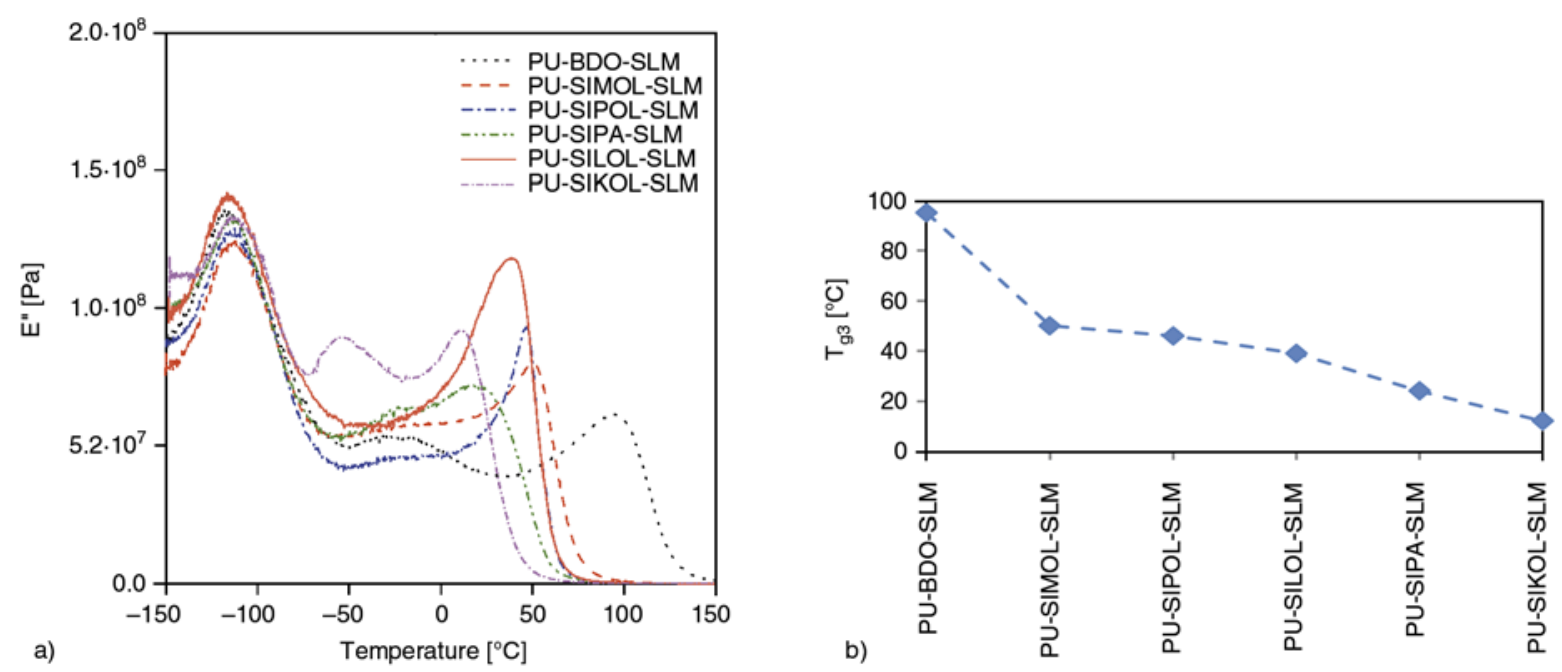

Figure 9. Loss moduli $\left(E^{\prime \prime}\right)$ of a selection of polymers of the same composition containing different chain extenders (a) and $T_{\mathrm{g} 3}$ values (determined from $\left.E^{\prime \prime}\right)$ of the same polymers (b)
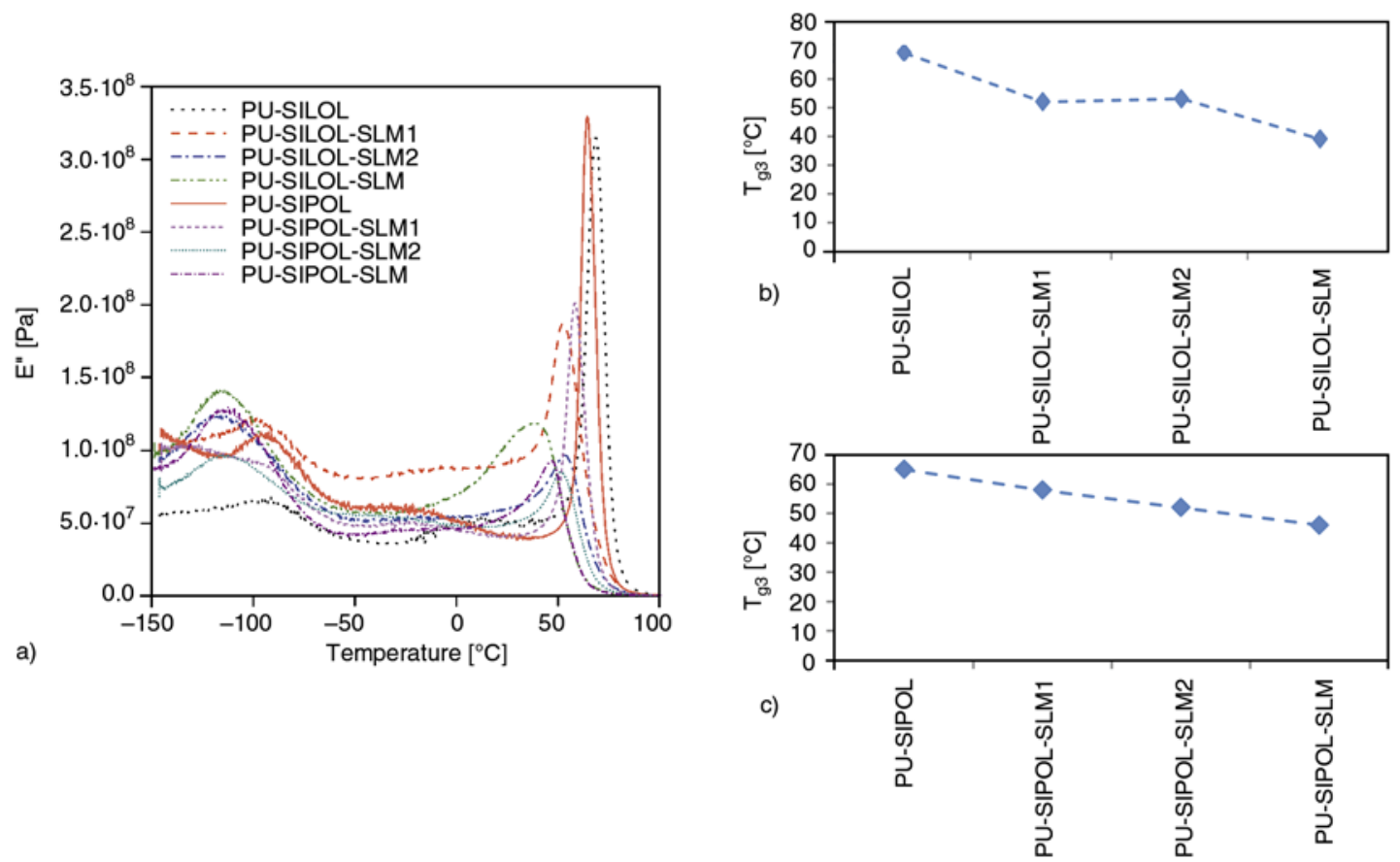

Figure 10. Loss moduli $\left(E^{\prime \prime}\right)$ of a selection of polymers of the same composition containing SILOL or SIPOL and a different amount of polysiloxane (a) and $T_{\mathrm{g} 3}$ values (determined from $\left.E^{\prime \prime}\right)$ of the same polymers (b-c)

PU-SIPOL-SLM stands out with higher UTS than it could be expected according to its $T_{\mathrm{g} 3}$. It suggests that SIPOL might form an optimal HS structure with MDI.

We made two series to illustrate the effect of the increasing polysiloxane content (Figure 10a-10c). PU-SILOL and PU-SIPOL did not contain SLM polysiloxane soft segments, while the other samples were prepared with increasing amount of SLM. The glass transition temperatures of the Si-O-Si units were well defined also in PU-SILOL and PU-SIPOL where only disiloxanes were present. As the poly- siloxane content increased, $T_{\mathrm{g} 1}, T_{\mathrm{g} 2}$, and $T_{\mathrm{g} 3}$ decreased. The decrease of $T_{\mathrm{g} 2}$ and $T_{\mathrm{g} 3}$ can be a result of several impacts. Besides other structural effects the decreasing theoretical cross-link density has a significant influence as the siloxane content increases [23]. Changes in $E^{\prime \prime}$ loss moduli at $T_{\mathrm{g} 3}$ did not show regularity as a function of the increasing polysiloxane content. $E^{\prime \prime}$ values did not decrease as the cross-link density increased [15]. It corresponds to our theory: the cross-link density does not have a dominant effect and the aforementioned two effects operate at the same time. 


\subsection{Cross-link density}

Swelling measurements were carried out in order to determine the cross-link density of the investigated samples. Different solvents (toluene, n-butyl acetate, ethanol, isopropyl alcohol) were tested to find the best solvent for our PSiUs. $Q_{\mathrm{s}}$ characterises the swelling properties according to Equation (2):

$Q_{\mathrm{s}}=1+\frac{\rho_{\mathrm{p}}}{\rho_{0}} \frac{m_{\mathrm{s}}-m_{\mathrm{d}}}{m_{\mathrm{d}}}$

where $\rho_{\mathrm{p}}$ is the density of the polymer, $\rho_{0}$ the density of the solvent, $m_{\mathrm{s}}$ is the weight of the swollen sample, and $m_{\mathrm{d}}$ is the weight of the dried sample [24].

According to $Q_{\mathrm{s}}$ THF was chosen for the solvent of this study.

Swelling of networks is related to their cross-link density, which can be calculated according to the Flory-Rhener equation (Equation (3)):

$$
\frac{\rho_{\mathrm{p}}}{\bar{M}_{\mathrm{c}}}=\nu_{\mathrm{e}}=\frac{-\left[\ln \left(1-\nu_{2}\right)+\nu_{2}+\chi \nu_{2}^{2}\right]}{V_{\mathrm{s}}\left(\nu_{2}^{\frac{1}{2}}+\frac{\nu_{2}}{2}\right)}
$$

where $\rho_{\mathrm{p}}$ is the polymer density, $\bar{M}_{\mathrm{c}}$ is the average molecular weight between two cross-links, $v_{2}$ is the volume fraction of the polymer in the swollen gel $\left(v_{2}=1 / Q_{\mathrm{S}}\right), V_{\mathrm{S}}$ is the specific volume of the solvent (for THF $V_{\mathrm{s}}$ is $81.9 \mathrm{~cm}^{3} \cdot \mathrm{mol}^{-1}$ ), and $\chi$ is the polymer-solvent interaction parameter that can be calculated with Equation (4):

$\chi=\chi_{\mathrm{s}}+\chi_{\mathrm{H}} \approx 0.34+\frac{V_{\mathrm{s}}}{R T}\left(\delta_{0}-\delta_{\mathrm{p}}\right)^{2}$

where $\chi_{\mathrm{s}}$ and $\chi_{\mathrm{H}}$ are the entropic and enthalpic contributions, $\delta_{0}$ and $\delta_{\mathrm{p}}$ are the solubility parameters of solvent and polymer, respectively [24].

As PSiU networks of this study have the highest equilibrium swelling values in THF, we can assume that $\delta_{\mathrm{p}}$ of the networks is very close to $\delta_{0}$ of THF, thus $\delta_{0} \approx \delta \mathrm{p}$ and $\chi \approx 0.34$.

Cross-link density is related also to the rubbery plateau modulus according to Equation (5):

$E=\left(\nu_{\mathrm{e}}-h \mu\right) R T$

where $v_{\mathrm{e}}$ is the cross-link density, $h$ is an empirical parameter, $\mu$ represents the elastically active crosslinks, $R$ is the universal gas constant, and $T$ is the temperature in Kelvin [14]. In a highly cross-linked network $h$ approximately equals 0 , and we can assume that $E$ equals the storage modulus $E^{\prime}$ on the rubbery plateau (it means usually $T=T_{\mathrm{g} 3}+80^{\circ} \mathrm{C}$; where $T_{\mathrm{g} 3}$ is determined from $\tan \delta$ ), thus $M_{\mathrm{c}}$ can be calculated according to Equation (6) [14]:

$M_{\mathrm{c}}=\frac{\rho_{\mathrm{p}} R T}{E^{\prime}}$

The density of the investigated PSiU networks ranges between 1.06 and $1.24 \mathrm{~g} \cdot \mathrm{cm}^{-3}, Q_{\mathrm{s}}$ was calculated according to Equation (2), and $M_{\mathrm{c}}$ was determined in different ways. The theoretical average molecular weight between cross-links $\left(M_{\mathrm{c} \text {,theo }}\right)$ can be calculated from the compositions. $M_{\mathrm{c}, \text { theo }}$ gives the theoretical number of cross-links formed by the covalent bonds of Lupranol-1301. $M_{\mathrm{c}}$ can be determined according to Equation (3) from swelling measurements $\left(M_{\mathrm{c}, \text { swell }}\right)$, and $M_{\mathrm{c}}$ is related to the rubbery plateau modulus as described in Equation (6) $\left(M_{\mathrm{c}, \mathrm{E}^{\prime}}\right)$. All the aforementioned data are listed in Table $9,\left(M_{\mathrm{c}, \mathrm{E}^{\prime}}\right.$ is given provided there was a rubbery plateau, PU-SIPOL and PU-SILOL-SLM had a yield).

At the first six samples in Table 9 we determined higher $M_{\mathrm{c}, \mathrm{swell}}$-s than $M_{\mathrm{c}, \text { theo-s }}$ which were calculated from the compositions. In fact especially PUSIKOL was less cross-linked than it was designed. These differences indicate that not all the hydroxyl groups of Lupranol-1301 reacted with isocyanates. These samples did not contain longer soft segments, and all the monomers were very reactive, so they might have reacted too fast, and at a certain degree of cross-linking the movement of the monomers could have been hindered, so the reaction stopped before it was completed.

The samples containing SLM polysiloxane were found to be more cross-linked than it was expected. The difference between $M_{\mathrm{c} \text {,theo }}$ and $M_{\mathrm{c} \text {,swell }}$ is especially big at the PU-CE-SLM series. Though $M_{\mathrm{c}, \mathrm{E}^{\prime}}$ values seem to be less accurate in the case of our samples, they support the results of the swelling measurements. The deviation of $M_{\mathrm{c}}$ values determined with different methods is reasonable as described in previous works [25-27], but they can be used for comparison. $M_{\mathrm{c} \text {, theo }}$ calculated from the composition takes only the possible chemical crosslinks into account, $M_{\mathrm{c}, \text { swell }}$ includes the real chemical and physical cross-links while $M_{\mathrm{c}, \mathrm{E}^{\prime}}$ determined from mechanical characteristics bears usually a negative deviation from $M_{\mathrm{c}, \text { swell }}$. These low empirical $M_{\mathrm{c}}$ values could indicate strong interactions 
Table 9. Polymer density $\left(\rho_{\mathrm{p}}\right)$, swelling $\left(Q_{\mathrm{s}}\right)$, theoretical $\left(M_{\mathrm{c}, \text { theo }}\right)$ and empirical molecular weights between cross-links $\left(M_{\mathrm{c}, \mathrm{swell}} ; M_{\mathrm{c}, \mathrm{E}^{\prime}}\right)$

\begin{tabular}{|c|c|c|c|c|c|}
\hline Sample name & $\begin{array}{c}\rho_{p} \\
{\left[\mathrm{~g} \cdot \mathrm{cm}^{-3}\right]}\end{array}$ & $\mathbf{Q}_{\mathbf{s}}$ & $\begin{array}{c}\mathbf{M}_{\mathrm{c}, \text { theo }} \\
{\left[\mathrm{g} \cdot \mathrm{mol}^{-1}\right]}\end{array}$ & $\begin{array}{c}\mathbf{M}_{\mathbf{c}, \mathbf{s w e l l}} \\
{\left[\mathbf{g} \cdot \mathbf{m o l}^{-1}\right]}\end{array}$ & $\begin{array}{c}\mathbf{M}_{\mathrm{c}, \mathrm{E}^{\prime}} \\
{\left[\mathrm{g} \cdot \mathrm{mol}^{-1}\right]}\end{array}$ \\
\hline PU & 1.15 & 3.03 & 1427 & 1481 & - \\
\hline PU-SIMOL & 1.15 & 3.45 & 1780 & 2040 & - \\
\hline PU-SIPOL & 1.13 & 4.15 & 1893 & 3102 & $-^{*}$ \\
\hline PU-SILOL & 1.18 & 3.48 & 2069 & 2143 & 2345 \\
\hline PU-SIPA & 1.12 & 4.12 & 2253 & 3018 & - \\
\hline PU-SIKOL & 1.14 & 5.92 & 2237 & 6831 & - \\
\hline PU-BDO-SLM & 1.16 & 2.78 & 9480 & 1197 & 1090 \\
\hline PU-SIMOL-SLM & 1.15 & 4.38 & 10520 & 3569 & 2466 \\
\hline PU-SIPA-SLM & 1.11 & 3.72 & 11960 & 2357 & 1787 \\
\hline PU-SIKOL-SLM & 1.13 & 4.72 & 12800 & 4146 & 2106 \\
\hline PU-SILOL-SLM1 & 1.09 & 3.36 & 2319 & 1814 & 1110 \\
\hline PU-SILOL-SLM2 & 1.14 & 3.57 & 3056 & 2197 & 1922 \\
\hline PU-SILOL-SLM & 1.17 & 5.90 & 11960 & 6954 & $-^{*}$ \\
\hline PU-SIPOL-SLM1 & 1.14 & 3.48 & 2143 & 2066 & 1426 \\
\hline PU-SIPOL-SLM2 & 1.11 & 3.93 & 2880 & 2657 & 1587 \\
\hline PU-SIPOL-SLM & 1.12 & 3.96 & 11080 & 2747 & 4622 \\
\hline
\end{tabular}

*yield at $T=T_{\mathrm{g} 3}+80^{\circ} \mathrm{C}$

between the segments, but DMTA results show rather strong phase separation, thus probably the excess of the isocyanates partially reacted with urethane bonds resulting in allophanate cross-links. As the theoretical cross-link density increases, the difference between the expected and measured $M_{\mathrm{c}}$ decreases. The aforementioned observation is reasonable considering that with less cross-linker agent the segment movements are more intense and it favours i.e. the reaction of the excess isocyanate groups with urethane bonds.

The degree of cross-linking has a strong effect on the $T_{\mathrm{g}}$ and on other physical properties but it is not dominant. The maximum of the $T_{\mathrm{g}}$ peaks varies in a wide range depending mostly on the polymer compositions.

\section{Conclusions}

According to the results of this study it was revealed that all the tested disiloxane chain extenders were suitable for preparing PSiU networks of good thermal stability and high tensile strength. The tensile strength and the hardness indicate that the structure of the disiloxane chain extenders has a strong effect on the physical properties. At constant polysiloxane content the longer chains the disiloxane possessed the greater flexibility and the lower tensile strength were obtained. The chain extenders of smaller molecular weight that is of shorter chain length gave tougher but still not brittle polymers of up to 66.5 MPa UTS. Increasing the polysiloxane content the tensile strength decreased, but even of $34-36 \%$ siloxane content the tensile strength decreased only to 32-33 MPa when SIPOL or SIMOL was applied. Except for two, all the samples were found to be potentially good coating materials as they showed a good adhesion to aluminum and a good shock resistance. A set of samples of the highest tensile strength was investigated by isothermal thermogravimetry, and also the changes in the tensile strength and hardness were followed at 120 and $170^{\circ} \mathrm{C}$. At these temperatures we represented possible ambient conditions that can affect PSiU polymers. Except for SILOL all samples showed a good thermal stability and none of them decomposed at these temperatures over a week.

The thermogravimetric analysis revealed that using disiloxane chain extenders the degradation of the urethane bonds cannot be influenced, still they decompose at about $220-270^{\circ} \mathrm{C}$. However, the different chain extenders have effect on the further shape of the TG curves, and usually with higher siloxane content the degradation slows down at the range of $50-80 \%$ weight loss.

DMTA studies were carried out to determine glass transition temperatures. Two or three peaks were distinguished on $E^{\prime \prime}$ (and also on $\tan \delta$ curves), the first of them belongs to the siloxane soft segments $\left(-107 \ldots-92^{\circ} \mathrm{C}\right)$, the second might indicate an interphase containing mostly the cross-linker $(-50 \ldots$ $\left.-10^{\circ} \mathrm{C}\right)$, and the third one belongs to the hard segments $\left(43-78^{\circ} \mathrm{C}\right) . T_{\mathrm{g} 3}$ was found to be the most sen- 
sitive to the changes in the polymer composition. $T_{\mathrm{g} 3}$ decreases significantly with increasing chain extender chain length and with increasing polysiloxane content.

In summary, the chain length of the applied chain extender, the polysiloxane content and the crosslink density together determine the final characteristics of the polymer dominantly. Varying the structure of the disiloxane, the ratio of the cross-linker and the polysiloxane SSs polymers can be designed and synthesized with diverse physical properties for different purposes.

\section{Acknowledgements}

The authors thank Zoltán Demjén (Elastogran) and András Szabó (MagyarLakk Kft.) for the base chemicals.

\section{References}

[1] Kozakiewicz J.: Polysiloxaneurethanes: New polymers for potential coating applications. Progress in Organic Coatings, 27, 123-131 (1996).

DOI: 10.1016/0300-9440(95)00527-7

[2] Prabu A. A., Alagar M.: Mechanical and thermal studies of intercross-linked networks based on siliconized polyurethane-epoxy/unsaturated polyester coatings. Progress in Organic Coatings, 49, 236-243 (2004).

DOI: 10.1016/j.porgcoat.2003.09.018

[3] Eberhart A., Zhang Z., Guidoin R., Laroche G., Guay L., De la Faye D., Batt M., King M. W.: A new generation of polyurethane vascular prostheses: Rara avis or ignis fatuus? Journal of Biomedical Materials Research, 48, 546-558 (1999).

DOI: 10.1002/(SICI)1097-4636(1999)48:4<546::AIDJBM22>3.0.CO;2-V

[4] Benrashid R., Nelson G. L.: Synthesis of new siloxane urethane block copolymers and their properties. Journal of Polymer Science Part A: Polymer Chemistry, 32, 1847-1865 (1994).

DOI: $10.1002 /$ pola.1994.080321006

[5] Stanciu A., Airinei A., Timpu D., Ioanid A., Ioan C., Bulacovschi V.: Polyurethane/polydimethylsiloxane segmented copolymers. European Polymer Journal, 35, 1959-1965 (1999).

DOI: $10.1016 / \mathrm{S} 0014-3057(98) 00294-8$

[6] Wang L. F., Ji Q., Glass T. E., Ward T. C., McGrath J. E., Muggli M., Burns G., Sorathia U.: Synthesis and characterization of organosiloxane modified segmented polyether polyurethanes. Polymer, 41, 5083-5093 (2000).

DOI: $10.1016 / \mathrm{S} 0032-3861(99) 00570-4$
[7] Hernandez R., Weksler J., Padsalgikar A., Runt J.: Microstructural organization of three-phase polydimethylsiloxane-based segmented polyurethanes. Macromolecules, 40, 5441-5449 (2007).

DOI: $10.1021 / \mathrm{ma} 070767 \mathrm{c}$

[8] Liao S. K., Jang S. C., Lin M. F.: Phase behavior and mechanical properties of siloxane-urethane copolymer. Journal of Polymer Research, 12, 103-112 (2005). DOI: $10.1007 / \mathrm{s} 10965-004-2501-7$

[9] Yilgor I., Yilgor E.: Structure-morphology-property behavior of segmented thermoplastic polyurethanes and polyureas prepared without chain extenders. Polymer Reviews, 47, 487-510 (2007).

DOI: $10.1080 / 15583720701638260$

[10] Pergal M. V., Antić V. V., Ostojić S., Marinović-Cincović M., Đonlagić J.: Influence of the content of hard segments on the properties of novel urethane-siloxane copolymers based on a poly( $\varepsilon$-caprolactone)-b-poly (dimethylsiloxane)-b-poly( $\varepsilon$-caprolactone) triblock copolymer. Journal of the Serbian Chemical Society, 76, 1703-1723 (2011). DOI: $10.2298 / \mathrm{JSC} 110307146 \mathrm{P}$

[11] Adhikari R., Gunatillake P. A., McCarthy S. J., Meijs G. F.: Low-modulus siloxane-based polyurethanes. I. Effect of the chain extender 1,3-bis(4-hydroxybutyl) 1,1,3,3-tetramethyldisiloxane (BHTD) on properties and morphology. Journal of Applied Polymer Science, 83, 736-746 (2002).

DOI: $10.1002 / a p p .2268$

[12] Adhikari, R., Gunatillake P. A., McCarthy S. J., Bown M., Meijs G. F.: Low-modulus siloxane-polyurethanes. Part II. Effect of chain extender structure on properties and morphology. Journal of Applied Polymer Science, 87, 1092-1100 (2003).

DOI: 10.1002/app.11558

[13] Chuang F. S., Tsen W. C., Shu Y. C.: The effect of different siloxane chain-extenders on the thermal degradation and stability of segmented polyurethanes. Polymer Degradation and Stability, 84, 69-77 (2004). DOI: $10.1016 /$ j.polymdegradstab.2003.10.002

[14] Džunuzović, J. V., Pergal M. V., Poręba R., Ostojić S., Lazić N., Spirkova M., Jovanović S.: Studies of the thermal and mechanical properties of poly(urethanesiloxane)s cross-linked by hyperbranched polyesters. Industrial and Engineering Chemistry Research, 51, 10824-10832 (2012).

DOI: $10.1021 / \mathrm{ie} 300927 \mathrm{z}$

[15] Stanciu A., Bulacovschi V., Lungu M., Vlad S., Balint S., Oprea S.: Mechanical behaviour of crosslinked poly(ester-siloxane) urethanes. European Polymer Journal, 35, 2039-2044 (1999).

DOI: $10.1016 / \mathrm{S} 0014-3057(98) 00286-9$

[16] Yeh J-T., Shu Y-C.: Characteristics of the degradation and improvement of the thermal stability of poly(siloxane urethane) copolymers. Journal of Applied Polymer Science, 115, 2616-2628 (2010).

DOI: $10.1002 /$ app. 29023 
[17] Chuang F-S., Tsi H-Y., Chow J-D., Tsen W-C., Shu YC., Jang S-C.: Thermal degradation of poly(siloxaneurethane) copolymers. Polymer Degradation and Stability, 93, 1753-1761 (2008).

DOI: $10.1016 /$ j.polymdegradstab.2008.07.029

[18] Liptay G., Nagy J., Weis J. C., Borbely-Kuszmann A.: Thermoanalytical investigations of silicone caoutchouc polymers and silicone rubbers, I. Journal of Thermal Analysis, 32, 1421-1433 (1987).

DOI: $10.1007 / \mathrm{bf01913343}$

[19] Liao S. K., Jang S. C., Lin M. F.: Thermal degradation of imide-containing siloxane-urethane copolymer. Journal of Polymer Engineering, 27, 197-217 (2007). DOI: 10.1515/POLYENG.2007.27.3.197

[20] Pusztai E., Nagy J., Wagner Ö.: Synthesis and characterization of some bis(hydroxyalkyl)- and bis(hydroxyester)-functionalized disiloxanes. Main Group Metal Chemistry, 35, 91-97 (2012).

DOI: $10.1515 / \mathrm{mgmc}-2012-0010$

[21] Ionescu M.: Chemistry and technology of polyols for polyurethanes. Rapra Technology Limited, Shropshire, UK (2005).

[22] Meier-Westhues U.: Polyurethanes: Coatings, adhesives and sealants. Vincentz, Hannover (2007).

[23] Andrady A. L., Sefcik M. D.: Glass transition in poly (propylene glycol) networks. Journal of Polymer Science Part B: Polymer Physics Edition, 21, 2453-2463 (1983).

DOI: $10.1002 /$ pol.1983.180211203
[24] Burel F., Feldman A., Bunel C.: Hydrogenated hydroxyterminated polyisoprene (HHTPI) based urethane network: Network properties. Polymer, 46, 483-489 (2005).

DOI: 10.1016/j.polymer.2004.11.027

[25] Sekkar V., Bhagawan S. S., Prabhakaran N., Rao M. R., Ninan K. N.: Polyurethanes based on hydroxyl terminated polybutadiene: Modelling of network parameters and correlation with mechanical properties. Polymer, 41, 6773-6786 (2000). DOI: $10.1016 / \mathrm{S} 0032-3861(00) 00011-2$

[26] Sekkar V., Narayanaswamy K., Scariah K. J., Nair P. R., Sastri K. S., Ang H. G.: Evaluation by various experimental approaches of the crosslink density of urethane networks based on hydroxyl-terminated polybutadiene. Journal of Applied Polymer Science, 103, 3129-3133 (2007).

DOI: 10.1002/app.24751

[27] Sekkar V.: Comparison between crosslink densities derived from stress-strain data and theoretically data evaluated through the $\alpha$-model approach for a polyurethane network system based on hydroxyl terminated polybutadiene and isophorone-diisocyanate. Journal of Applied Polymer Science, 117, 920-925 (2010). DOI: 10.1002/app.31643 